\title{
O QUE É O ESTATUTO DE UM INTELECTUAL? A PIROTECNIA E A PARRHESIA COMO INTRODUÇÃO Á VIDA NÃO FASCISTA
} WHAT IS THE STATUTE OF AN INTELLECTUAL? PYROTECHNICS AND PARRHESIA AS AN INTRODUCTION TO NON-FASCIST LIFE

Rodrigo Diaz de Vivar Y Soler

Universidade Federal de Santa Catarina, Florianópolis/SC, Brasil

\begin{abstract}
RESUMO
Este artigo caracteriza-se como uma análise transversal sobre um possível estatuto do intelectual desdobrado nas perspectivas das ferramentas conceituais da pirotecnia e da parrhesía a partir das contribuições de Michel Foucault. Os domínios desse estatuto são percorridos pelas argumentações elaboradas a partir da prática elencada em relação ao enfrentamento perante os jogos de poder, as estratégias de saber e os processos de subjetivação. Nesse sentido, tanto a pirotécnica quanto a parrhesía são possibilidades diretas de problematização às formas de totalização e às políticas de normalização que estão inscritas no emaranhado dos dispositivos.
\end{abstract}

Palavras-chave: estatuto; intelectual; Michel Foucault; pirotecnia; parrhesía.

\begin{abstract}
This article is characterized as a cross-sectional analysis of a possible status of intellectual perspectives deployed in the conceptual tools of pyrotechnics and parrhesia from the contributions of Michel Foucault. The areas covered by this statute are arguments drawn from the practice chosen in relation to the tackling before the power plays, to know the strategies and processes of subjectification. In this sense, both the fireworks and the parrhesia are possibilities of direct questioning of the forms of aggregation and standardization policies that are entered in the tangle of the devices.
\end{abstract}

Keywords: statute; intellectual; Michel Foucault; pyrotechnics; parrhesía.

\section{Introdução}

O texto intitulado $O$ Sujeito e o Poder (Foucault, 1995) apresenta um posicionamento estratégico adotado por Foucault em relação ao exercício da atividade política direcionada contra as formas de sujeição exercidas não pelos critérios dos modos de produção ou das ideologias, mas pela destruição dos jogos de identidade. Esse posicionamento acarreta um duplo efeito para a construção de um estatuto do intelectual a partir da segunda metade do século XX, quais sejam: o rompimento com as atividades obsoletas da prática política - tomada do Estado ou derrubada do Capital, por exemplo - e também a finitude da imagem do intelectual como sujeito engajado, em nome do nominalismo histórico referendado pela veia intempestiva das relações de força da desconstrução nietzschiana.
Em outras palavras, trata-se de construir uma formulação de estratégias que ocorrem na transversalidade. Rajachman (1987) nomeia essas estratégias como condutas pós-revolucionárias, uma vez que o que está em jogo é a recusa a toda forma de doutrinamento em nome de novas táticas que procuram problematizar a história, a política e a verdade. Entretanto, essa atitude não deve ser confundida como uma espécie de desmobilização política ou ainda como uma refração em relação à possibilidade de elaboração crítica sobre a sociedade em geral, mas sim como a condição de rompimento e desdobramento de ações pulverizadas no jogo entre atividade e reatividade, nos pequenos confrontos, nas infames políticas de (des) subjetivação e nos mecanismos de agenciamentos. Equivale dizer, portanto, que, enquanto o discurso revolucionário centralizou seus esforços na tentativa de promover uma transformação global da sociedade, a 
política pós-revolucionária empreendida por Foucault assume um papel de apontamento e investigação das lutas setorizadas que ocorrem na dispersão de todo e qualquer acontecimento.

Este artigo caracteriza-se como uma análise sobre um possível estatuto do intelectual desdobrado nas perspectivas das ferramentas conceituais da pirotecnia e da parrhesía a partir das contribuições de Michel Foucault. Os domínios desse estatuto são percorridos pelas argumentações elaboradas na prática, elencadas em relação ao enfrentamento perante os jogos de poder, as estratégias de saber e os processos de subjetivação, cujas ressonâncias estão inscritas na própria trajetória autobiográfica de Foucault, pois, de certa maneira, todos os seus escritos procuraram estabelecer um diagnóstico das evidências por meio da construção de um exercício político de uma vida não fascista. Nesse sentido, reconhece-se na construção textual de Foucault a criação de um gesto polêmico que intensifica o enfrentamento perante todas as formas de opressão e o combate às políticas de identidade por meio de um trabalho do sujeito sobre si mesmo, pois tanto a pirotécnica, quanto a parrhesía são possibilidades diretas de problematização às formas de totalização e às políticas de normalização, que estão inscritas no emaranhado dos dispositivos.

\section{A pirotecnia e a parrhesía como introdução à vida não fascista}

Numa entrevista concedida na década de 70 , Foucault (2006) anunciava-se não como historiador, nem como filósofo, mas como um pirotécnico. Um pirotécnico é alguém que produz artefatos que servem para a desconstrução. Ele observa com ceticismo o terreno no qual se encontra, procurando brechas no arenoso campo das práticas políticas visando à implosão de tudo aquilo que se coloca como verdade. Onde é fácil cavar? O que não irá resistir? Essas são as perguntas essenciais presentes na pirotecnia. Mas, poderíamos nos perguntar: como um pirotécnico desenvolve o seu trabalho? Quais seriam os seus objetos?

Essa pergunta recai sobre a trajetória autobiográfica de Foucault. Nesse sentido, é preciso reconhecer na sua autobiografia um fio condutor, uma problematização que se desdobra perante as demais: é preciso visualizar um Foucault/pirotécnico interessado em construir uma história política da verdade.

Uma história como problematização da verdade seria o ponto de partida para a emergência de um estatuto do intelectual em Foucault, de acordo com
Candiotto (2010). Esse estatuto está solidificado numa tarefa contemporânea que recai não sobre o hermetismo ou em direção de consciência - práticas tão comuns dos intelectuais do início do século XX -, mas sobre a estratégia da vida e da morte. Para Foucault (1979), o intelectual é aquele que corre perigo não por ser o portador de uma verdade universal, mas por estar municiado de um saber que pode tanto favorecer a vida, quanto exterminá-la.

Em todos os seus projetos políticos Foucault implicou-se no discurso o qual analisava. Foi assim com a loucura, quando escreveu História da Loucura na Idade Clássica (Foucault, s.d.), cuja proposta foi localizar uma experiência trágica da loucura como contraposição ao saber psiquiátrico. Foucault (s.d.) indica as condições de possibilidade da psiquiatria colocando-a em suspenso para mostrar como este saber não é o grande responsável pela elucidação dos mistérios da doença mental, mas que funciona como um dispositivo responsável pelo confinamento dos socialmente indesejáveis. Dessa forma, a psiquiatria que advoga para si a exclusividade sobre o tratamento da loucura, pode tranquilamente ter sua imagem associada à prática ritualística exercida nos tribunais da Inquisição, por exemplo. Construir uma história da loucura sob este ângulo implica em realizar o que Foucault (2002) chamou de arqueologia do silêncio, isto é, um rastreamento pelos arquivos de todas as vozes que foram silenciadas pelo saber psiquiátrico ao longo da história.

Proposta semelhante acontece com a publicação do dossiê Eu Pierre Riviere Que Degolei Minha Mãe, Minha Irmã e Meu Irmão (Foucault, 2003a). A monstruosidade desse obscuro caso de matricídio ocorrido na França durante a primeira metade do século XIX efetiva-se pelo significado singular que seu discurso produz. Pierre Riviere não deve ser analisado aos olhos de Foucault (2003a), pela dualidade culpado/ vítima, mas sim como um resultado de uma múltipla peça judiciária que condena ao esquecimento o infame. Essa infâmia só pode ser despertada quando se recorre aos arquivos para capturar o exato momento do seu desaparecimento. Dessa maneira, tal qual a figura do louco foi forçada a exilar-se nos confins do hospital psiquiátrico, o monstro e o assassino tornaram-se personagens que devem ser rechaçadas a qualquer custo existindo somente em breves passagens dos relatórios policiais e prontuários psiquiátricos.

Existe um terceiro elemento dessa implicação política que está presente em Vigiar e Punir (Foucault, 1999). Aparentemente encontramos um grande projeto neste livro que seria o de construir uma genealogia das prisões situada no contexto 
da modernidade - final do século XVIII. Mas, é preciso atentar-se para uma perspectiva menor que passa quase despercebida, porém é tão importante quanto. Trata-se do que Foucault (1999) chama de genealogia do indivíduo moderno. Quando passamos do primeiro para o segundo capítulo de Vigiar $e$ Punir (Foucault, 1999), é que podemos visualizar como a modernidade estruturou uma concepção de indivíduo diretamente atrelado às relações de poder. Um indivíduo atingido diretamente no peito por essas relações que o produzem segundo os critérios da norma presentes nos dispositivos disciplinares e nos mecanismos de sujeição. A partir dessa constatação é que podemos nos perguntar: que relação podemos estabelecer com a genealogia deste indivíduo e o aparecimento das prisões? A resposta para esse questionamento corresponde ao olhar de Foucault (1999), voltado para a realização de uma ilustração paradoxal das práticas de poder que são produzidas na nossa sociedade. Ou seja, se no nosso cotidiano o poder é praticado sorrateiramente por uma série de dispositivos que são aparentemente imperceptíveis, as penitenciárias denotam o seu lado mais explosivo. Aquilo que recusamos a aceitar: a dança macabra do esquartejamento dos corpos que é potencializada ao extremo no intramuros dessas instituições.

Existe mais um elemento da pirotecnia que está presente nos últimos trabalhos de Foucault: no caso, a problematização sobre a sexualidade. Foucault (1977, 1984, 1985) escreve três volumes sobre a história da sexualidade radicalmente diferentes. Enquanto que no primeiro volume ele está interessado em situar a sexualidade como uma construção histórica que liga a verdade do sujeito em relação ao seu sexo por meio do discurso - scientia sexualis (Foucault, 1977) -, o segundo volume dedica-se à construção de uma cartografia sobre o uso dos prazeres na Grécia antiga (Foucault, 1984), e o terceiro volume é dedicado à ética do cuidado de si como exercício espiritual presente nas escolas filosóficas do império romano (Foucault, 1985). O ponto que unifica esses três projetos está inscrito na concepção de sexualidade elencada por Foucault. Problematizar a sexualidade, de um ponto de vista político implica, segundo Foucault (1977), em reconhecer que jamais se alcançará a liberdade extrema de nossa subjetividade por meio da liberação do desejo ou do orgasmo como pressupunham Reich e Marcuse, por exemplo. A sexualidade seria, antes de tudo, um elemento de sujeição e não uma proposta libertadora. Portanto, a questão não é de ordem corporal, mas sim de experiência ética. Visto isso, a sexualidade só pode ser pensada como ferramenta transgressiva pelo ato em si, e não pela proposição de um discurso revolucionário que encontraria seu ponto de subversão numa possível autonomia do corpo perante a ideologia do cristianismo ou da sociedade burguesa.

Loucura, monstruosidade, criminalidade e sexualidade. Temas entrecruzados que desembocam na construção de uma história crítica da verdade e também de uma atividade política do intelectual orientada pelos critérios da pirotecnia. Contudo, é preciso lembrar: não devemos enxergar na emergência desse estatuto elementos capazes de nos direcionar para a formação política tal qual o grande revolucionário Lênin fez.

O que resta a fazer é chamar a atenção para a possibilidade de encontrarmos em cada uma dessas problematizações elementos capazes de ilustrar a pirotecnia articulada com uma experiência-limite da atitude de ser intelectual nos dias de hoje em tempos de uma cultura pós-aufklarung, na qual o pensamento de Foucault deve ser utilizado como uma caixa de ferramentas.

Mas, o que é uma caixa de ferramentas? É o próprio revezamento de discursos e de práticas, isto é, quando se utiliza de um conceito com a finalidade de potencializar determinadas práticas. Por exemplo, em 1971, Foucault (2003b), junto com outros intelectuais, articulou a construção do Grupo de Informações Sobre as Prisões. Ele participou desse grupo a partir do diagnóstico sobre as relações de poder na sociedade ocidental. A partir da constatação de que a sociedade sentenciava ao esquecimento os personagens infames produzidos pelos aparatos discursivos e pelos dispositivos de poder, a estratégia de combate desse grupo foi simples, porém carregada de intensidade. Era preciso fazer com que os condenados simplesmente falassem. Foucault (2003b) em momento algum tomou para si o dever de falar pelos outros. Preferiu adotar uma prática muito mais corrosiva: fazer do discurso infame um elemento produtor de estranhamento, causando o desconforto em todos aqueles que não admitiam sequer a colocação do problema. Eis aí uma maneira específica de se enfrentar o poder deslizando sobre a lâmina afiada do dispositivo sem tomar para si a responsabilidade de conduzir o outro.

A partir desse desenho sobre o papel do intelectual em Foucault como uma experiêncialimite, pode-se passar para o segundo momento deste texto que seria o de atrelar a pirotecnia a uma palavra grega que foi obscurecida e desprestigiada ao longo da história, sobretudo após a emergência do cristianismo: a parrhesía. Parrhesía significa, numa tradução livre, coragem da verdade. Este conceitoarma não foi trabalhado em nenhum livro de Foucault, aparecendo timidamente em uma ou duas entrevistas 
e mais especificamente nos seus dois últimos cursos ministrados no Collège de France (Foucault, 2010a, 2011).

A emergência da parrhesía implica numa atitude política para a prática do intelectual comprometido em problematizar os modos de assujeitamento presentes nas práticas sociais perante a coragem de enunciar a verdade, mesmo que isso implique o risco desse intelectual pagar com a vida pelo seu ato provocativo. Contudo, poder-se-ia colocar em evidência o caráter aparentemente contraditório dessa atitude desenhada por Foucault nesses últimos trabalhos a partir da correlação entre sua vida pessoal e aquilo que ele procurara combater em seus ditos e escritos, pois justamente ele, que agora vinha reivindicar o tema da fala livre e da coragem da verdade, jamais havia escrito sobre sua condição de homossexual. A situação torna-se ainda mais gritante se atentarmos para o fato de que nesta época - início da década de 80 - Foucault encontrava-se debilitado pela AIDS e tudo o que ele não fez foi escrever e falar sobre sua condição. Quando Jean-Paul Aron (1988) escreveu o seu testamento intelectual intitulado Mon SIDA, ele criticou Foucault por não abordar tal tema, nem ter convocado a imprensa para dizer simplesmente a verdade sobre si mesmo e sobre sua condição.

Esse paradoxo pode ser explicado pela característica mais importante da parrhesía. Ela é uma atitude performática por meio da qual o sujeito deve expressar a verdade, porém esta performatividade jamais deve assemelhar-se a um ato confessional. A confissão, segundo Foucault (1977), é uma forma de o sujeito interiorizar a verdade responsabilizando-se pelos seus atos. De proveniência cristã, a confissão é uma herança presente nos primeiros rituais de mortificação que é transportada para o contexto da modernidade pelas mãos do aparelho judiciário, do saber psiquiátrico e da psicanálise.

Já a parrhesía é pura exterioridade. Quando o sujeito possui a coragem aristocrática de falar, mesmo que pague com a vida por isso. Eis o primeiro traço da parrhesía. Aquele que fala deve sempre correr risco. Não existe espaço para responsabilização, nem muito menos adulação no discurso parrhesiástico.

Existem ainda mais alguns indicativos da parrhesía que são necessários para a sua composição performática. Além do risco, o discurso parrhesiástico é totalmente atravessado pela ironia e por um lirismo cínico. Em outas palavras, aquele que utiliza a parrhesía não possui receio em provocar o mal-estar somente pelo ódio, mas também pelo riso e pelo constrangimento.
Outra questão importante deve-se ao fato de que para haver parrhesía é necessário que insurja a voz de alguém com menos poder, perante outro com mais poder. Por exemplo, um professor não é um parrhesiástes porque, embora, ensine verdades para seus alunos, não assume nenhum risco nesse ato. Mas, o intelectual que se reporta a um governante apontando todas as fragilidades do seu governo é um parrhesiástes, pois coloca em risco sua própria vida para que a verdade venha à tona.

Existe ainda uma implicação ética para o exercício da parrhesía que ultrapassa o território da franqueza, no caso a ética. A implicação ética da parrhesía passa pela produção de uma relação do sujeito com ele mesmo, em que haja uma composição polifônica entre bios x verdade x logos. Sócrates foi a figura que levou ao extremo essa composição. Durante seu julgamento registrado na Apologia (Platão, 2008), ele afirma perante seus acusadores que, em vez de ser condenado à morte, deveria ser homenageado pelos políticos atenienses pela adoção de um estilo de vida que objetivava não a conquista de bens materiais ou prestígios políticos, mas a construção da possibilidade de viver de acordo com aquilo que ele acreditava ser o correto. Esta seria a implicação ética da parrhesía. Viver em consonância, numa atitude-limite com aquilo que se acredita, com aquilo que se produz.

A partir dessa aproximação da coragem com a franqueza, a ironia, a política e a ética, podemos associar a performatividade da parrhesía com o desenho do estatuto do intelectual pensado por Foucault. Se um intelectual, no contexto contemporâneo atravessa não um, mas vários campos de batalha, seu posicionamento agora representa a adoção de práticas políticas que ocorrem na transversalidade. O intelectual é uma máquina de guerra, mas essa guerra da qual ele participa não é a guerra pela derrubada do Capital, nem do Estado. A guerra a qual o intelectual pirotécnico e parrhesiástes faz parte é a guerra de guerrilha. Isto é, são as pequenas estratégias desenvolvidas no cotidiano que lhe interessa. As resistências, as transgressões e as práticas de liberdade. Linhas de fuga que se desdobram numa atividade em prol daqueles que se encontram amordaçados pelo poder, daqueles que se encontram mergulhados em formas de individualização menorizadas.

A atitude do intelectual na contemporaneidade encontra-se posicionada na proliferação das vozes infames que são acobertadas pelas normas e pelos valores da sociedade. A parrhesía aparece no momento em que se empreende um diagnóstico da condição do local onde se desenvolve a prática intelectual. Isto é, no exato instante em que se aponta para a sociedade 
o fato de que o grande desafio posto a todos os que pretendem atuar criticamente é, segundo Artièrs (2004), fazer ver aquilo que vemos, ou seja, enxergar no óbvio um elemento de problematização.

Isso é exatamente o que Foucault chama de questionar a política, a ética e a história a partir de questões que fazem parte do nosso tempo presente. De certa maneira, a pirotecnia e a parrhesía interpelam e atravessam os intelectuais nos dias de hoje, mostrando quão urgente é a construção de uma prática que seja referendada pela provocação e pela liberdade.

\section{Considerações finais}

Encaminhamos a conclusão deste artigo apoiando-nos num texto emblemático de Foucault (2010b). Esse texto foi publicado a título de prefácio da edição estadunidense do livro $O$ Anti-Édipo. Nesse prefácio, Foucault rende homenagem a um bispo do século XV chamado São Francisco de Sales (2009), que escreveu Filotéia: introdução à vida devota. A beleza desse texto absolutamente cristão é que ele dirige-se não aos exegetas do pensamento religioso, mas aos leigos. Aqueles que acreditavam na palavra de Deus é que deveriam tomar esse livro como um instrumento de aperfeiçoamento para a salvação da sua alma.

De certa maneira, Foucault (2010b) desdobra o objetivo inicial de São Francisco de Sales (2009), indicando que o exercício de uma vida não fascista é a tarefa mais singular no contexto das lutas políticas posteriores à segunda metade do Século $\mathrm{XX}$, as quais diversas nomenclaturas começam a ser problematizadas a partir do confronto imediato de grupos historicamente marginalizados, como os homossexuais e os negros, por exemplo, contra as políticas de totalização de identidade.

De certa forma, Foucault (2010b) convidanos a tomar não só os seus escritos, mas também a textualidade de Deleuze, Guatarri, Lacan, Lyotard, Althusser, Blanchot e vários outros como indicativos de uma introdução à vida não fascista, pois todos esses intelectuais construíram argumentações, buscando desprenderem-se cada qual a seu modo dos emaranhados do poder. Suas reflexões apontaram para a finitude das metanarrativas e a morte da Razão, do Sujeito e da Verdade.

Contudo, existem alguns adversários diretos dessa conduta contra os quais é preciso deflagrar uma guerra. São eles, segundo Foucault (2010b): os ascetas políticos, os militantes fervorosos, os burocratas revolucionários e os arautos da verdade. Eles estão a serviço de um tipo de fascismo. Não o de Estado, mas o fascismo que cada um carrega consigo. Sendo assim, experienciar o exercício político de uma vida não fascista significa, para o intelectual, partir à procura de construção de uma ética direcionada pela pergunta formulada por Foucault (2010b, p. 13): "How does one keep from being fascist, even (especially) when one bilieves oneself to be a revolutionary militant?". Poderse-ia acrescentar outro questionamento a este: qual o limite que separa uma atividade crítica de uma prática autoritária? A resposta para esses dois questionamentos não pode ser encontrada em nenhum manual. Ela deve ser construída mediante o afastamento e a recusa do intelectual contra toda forma de sujeição.

Deflagrar uma luta contra esse processo implica na construção de uma askesis - um trabalho do sujeito sobre si mesmo - desdobrada em sete apontamentos apresentados por Foucault (2010b): em primeiro lugar, deve-se procurar criar uma prática política livre da paranoia unitária e totalizante. Em segundo lugar, deve-se experienciar o pensamento de modo que exista proliferação, justaposição e a disjunção. Em terceiro lugar, deve-se recusar a velha tese de que o poder é unicamente uma instância repressiva. Sendo assim, a tarefa seria a de se pensar o poder a partir da capilaridade, da multiplicidade e da diferença. Em quarto lugar, é preciso ter clareza de que o verdadeiro guerreiro é aquele que nunca abandona o combate. Em quinto lugar, deve-se utilizar o pensamento de modo a possibilitar a proliferação da multiplicidade. Como sexta condição, devemos todos nos (des)individualizar, ou seja, devemos desconstruir as velhas categorias de indivíduo, bem como os obsoletos papéis que são impostos aos sujeitos, em nome de um deslocamento que possibilite a aplicação de novos arranjos e a promoção de novas subjetividades. Finalmente, em hipótese alguma, deve-se morrer de amor pelo poder. É importante lembrar que todo esse conjunto de prescrições somente torna-se possível no exato momento em que os efeitos das relações de poder, das estratégias de saber e dos processos de subjetivação são neutralizados, sentenciando ao esfacelamento as formas miúdas de fascismo que insistem em compor a tirania de nossas vidas.

\section{Referências}

Aron, J.P. (1988). Mon SIDA. Paris: Christian Bourgois.

Artièrs, P. (2004). Dizer a atualidade: o trabalho de diagnóstico em Michel Foucault. In F. Gros (Org.), Foucault: a coragem da verdade (pp. 2-23). São Paulo: Parábola Editorial.

Candiotto, C. (2010). Foucault e a crítica da verdade. Belo Horizonte; Curitiba: Autêntica/Champagnat.

Foucault, M. (s.d.). História da Loucura na Idade Clássica. São Paulo: Perspectiva. 
Foucault, M. (1977). História da sexualidade I: a vontade de saber. Rio de Janeiro: Graal.

Foucault, M. (1979). Verdade e poder. In M. Foucault, Microfisica do poder (pp. 1-14). Rio de Janeiro: Graal.

Foucault, M. (1984). História da sexualidade II: o uso dos prazeres. Rio de Janeiro: Graal.

Foucault, M. (1985). História da sexualidade III: o cuidado de si. Rio de Janeiro: Graal.

Foucault, M. (1995). O sujeito e o poder. In H. Dreyfus \& P. Rabinow, Michel Foucault: uma trajetória filosófica para além do estruturalismo e da hermenêutica (pp. 208 - 239). Rio de Janeiro: Forense Universitária.

Foucault, M. (1999). Vigiar e punir. Petrópolis, RJ: Vozes.

Foucault, M. (2002). Prefácio (Folie et dérasion). In M. Foucault, Problematização do Sujeito: psicologia, psiquiatria e psicanálise (pp. 152 - 161). Rio de Janeiro: Forense Universitária.

Foucault, M. (2003a). Eu, Pierre Rivière, que degolei minha mãe, minha irmã e meu irmão. Rio de Janeiro: Graal.

Foucault, M. (2003b). Manifesto do G.I.P. In M. Foucault, Estratégia, Poder-Saber (pp. 1 - 03). Rio de Janeiro: Forense Universitária.

Foucault, M. (2006). Eu sou um pirotécnico. In M. Foucault, Entrevistas (pp.69-75). São Paulo: Graal.

Foucault, M. (2010a). Governo de si e dos outros. São Paulo: Martins Fontes.

Foucault, M. (2010b). Introduction to the Non-Fascist Life. In G. Deleuze \& F. Guattari, Anti - Oedipus: capitalism and schizophrenia (pp. $11-13$ ). New York: Penguin Classics.

Foucault, M. (2011). A coragem da verdade. São Paulo: Martins Fontes.
Platão. (2008). Apologia de Sócrates. Porto Alegre: L\&PM.

Rajachman, J. (1987). Foucault: a liberdade da filosofia. Rio de Janeiro: Jorge Zahar.

Sales, S. F. (2009). Filotéia ou Introdução à vida devota. Petrópolis, RJ: Vozes.

Recebido em: 18/01/2012

Revisão em: 09/08/2012

Aceite em: 14/07/2013

Rodrigo Diaz de Vivar Y Soler é Bacharel em Psicologia pela UNESC, Mestre em Psicologia pela UFSC, Doutorando em Psicologia pela UFSC e Professor do Centro Universitário Estácio de Sá/SC. Endereço: Universidade Federal de Santa Catarina - UFSC, Florianópolis/SC, Brasil. CEP 88040-900. Email: diazsoler@gmail.com

\section{Como citar:}

Soler, R. D. V. (2013). O que é o estatuto de um intelectual? A pirotecnia e a parrhesía como introdução à vida não fascista. Psicologia \& Sociedade, 25(3), 504-509. 